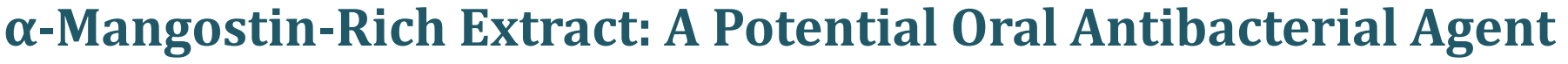 Prepared by Green Extraction
}

\section{Meah MS ${ }^{1}$ and Panichayupakaranant $\mathrm{P}^{1,2 *}$}

${ }^{1}$ Department of Pharmacognosy and Pharmaceutical Botany, Faculty of Pharmaceutical Sciences, Prince of Songkla University, Thailand

${ }^{2}$ Phytomedicine and Pharmaceutical Biotechnology Excellence Center, Faculty of Pharmaceutical Sciences, Prince of Songkla University, Thailand

\section{Research Article}

Volume 4 Issue 2

Received Date: June 03, 2020

Published Date: July 06, 2020

DOI: $10.23880 /$ ipcm-16000201

*Corresponding author: Pharkphoom Panichayupakaranant, Faculty of Pharmaceutical

Sciences, Prince of Songkla University, Thailand, Tel: 66-74-288980; Email: pharkphoom.p@psu.ac.th

\section{Abstract}

The purpose of this study was to prepare $\alpha$-mangostin-rich extract (AME) using a green microwave extraction together with a simple one-step green fractionation method on a hydrophobic resin column. Based on the established method, AME containing $95 \% \mathrm{w} / \mathrm{w} \alpha$-mangostin content was obtained with an extract yield of $0.46 \% \mathrm{w} / \mathrm{w}$ dry plant powder. In addition, investigation of its antibacterial activity against oral pathogenic bacteria, including Streptococcus mitis, S. mutans, S. pyogenes and Bacillus subtilis, compared with the standard marker, $\alpha$-mangostin found that AME exhibited strong antibacterial activities, which were equivalent to those of $\alpha$-mangostin (MICs and MBCs of 0.5-2 and 4-16 $\mu \mathrm{g} / \mathrm{mL}$, respectively). Moreover, AME exhibited equivalent antibacterial activity against Propionibacterium acnes when compared to the pure $\alpha$-mangostin (MIC and MBC of 2 and $8 \mu \mathrm{g} / \mathrm{mL}$, respectively). A chemical stability evaluation found that AME was stable through a period of 16 weeks, when kept in a well-closed container protected from light and stored either at $4 \pm 2$ or $30 \pm 2^{\circ} \mathrm{C}$. On the other hand, AME was instable when exposed to light after 3 weeks of storage. The stability evaluation under accelerated conditions (75\% relative humidity, at $45^{\circ} \mathrm{C}$ ) implied that $\mathrm{AME}$ has a shelf-life of at least two years.

Keywords: $\alpha$-Mangostin; Green Extraction; Microwave Extraction; Stability; Antibacterial; Garcinia mangostana

\section{Introduction}

General methods for preparation of herbal extracts involve uses of organic solvents such as methanol, ethyl acetate, acetone, chloroform, dichloromethane, hexane, etc. Their volatile, flammable, and toxic properties are of concern for human beings and the environment [1]. The conventional methods used for preparation of herbal extracts, i.e. maceration and heat reflux extraction, are time-consuming and require large amounts of organic solvents [2]. Therefore, a green and efficient extraction that is free from toxic organic solvents is essential for the preparation of active constituentrich extract for pharmaceutical and cosmetic applications [3]. A green extraction concept has recently been applied to the development of commercialized herbal products. It is based on the design of extraction procedures that can reduce energy consumption, promote the use of alternative green solvents, and produce a safe and high-quality extract [4]. Recently, a microwave-assisted extraction has been proven as a green extraction method used for commercial preparation of herbal extracts [5-7]. This method not only produces a high-quality herbal extract, but also reduces production costs.

Generally, a pure phytochemical exhibits higher biological activity than its plant extract. However, the applications of pure phytochemicals for phytopharmaceutical industries are rare due to their cost. A purification of phytochemicals involves multi-stage, time-consuming and energy-intensive processes that require a large amount of toxic organic solvents, ultimately increasing their production costs. In addition, most pure bioactive phytochemicals are not 


\section{International Journal of Pharmacognosy \& Chinese Medicine}

available commercially. Recently, an active constituent-rich extract has been introduced to overcome this problem. Some active constituent-rich extracts have been reported to produce the equivalent biological effects like their pure marker compounds [8]. This phenomenon may be due to their high contents of bioactive compounds and a synergistic effect with other derivatives.

Garcinia mangostana L. (mangosteen; Clusiaceae family) is an important economic plant grown in Eastern and Southern Thailand. The pericarps of G. mangostana are enriched in $\alpha$-mangostin (Figure 1), a bioactive prenylated xanthone $[9,10]$. $\alpha$-Mangostin possess various biological effects, such as antibacterial, antifungal, anti-inflammatory and anti-cancer activities [11]. The extract of pericarps has been applied in a mouthwash, which exhibited antibacterial activity against $S$. mutans with a MIC of $0.625 \mu \mathrm{g} / \mathrm{mL}$ equivalent to chlorhexidine, an antiseptic used for dental plaque control $[12,13]$. The dichloromethane extract of mangosteen pericarp has been reported as effective against dental plaque forming bacteria such as Staphylococcus, Streptococcus, Streptobacillus and Monococcus spp. [14]. Moreover, $\alpha$-mangostin has exhibited antibacterial activity against $S$. pyogenes and P. acnes with MICs of 6.25 and 0.78 $\mu \mathrm{g} / \mathrm{mL}$, respectively [15].

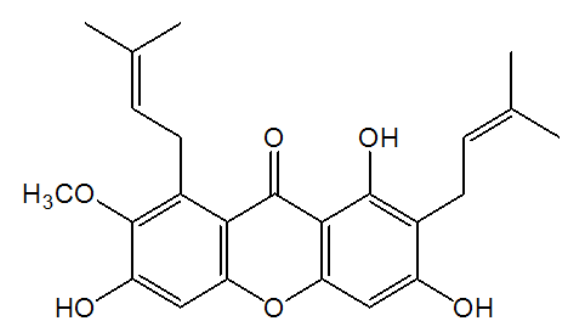

Figure 1: Chemical structure of $\boldsymbol{\alpha}$-mangostin.

The present study, therefore, used $\alpha$-mangostin as the bioactive marker for preparation of $\alpha$-mangostin-rich extract (AME) using a microwave-assisted extraction and alternative green solvent together with a simple one-step fractionation on a hydrophobic resin column. The extract was then evaluated for antibacterial activity compared with its standard marker. In addition, the stability of $\alpha$-mangostin in AME during storage was determined. These results are essential for further drug development.

\section{Materials and Methods}

\section{Plant Materials and Chemicals}

Dried powders of $G$. mangostana were purchased from Charoensuk Pharma Supply (Nakhon Pathom, Thailand). Ampicillin and Diaion HP-20 resin were from Sigma-Aldrich (Steinheim, Germany). $\alpha$-Mangostin was previously purified by the method described by Ahmad, et al. [15]. Formic acid, brain heart infusion (BHI) and agar were from the Becton, Dickinson, and Company (New Jersey, USA). Polyethylene glycol 400 (PEG 400, pharmaceutical grade), acetonitrile and methanol (HPLC grades) were from RCI Labscan (Bangkok, Thailand). Ethanol (commercial grade) was from High Science Ltd. (Hat-Yai, Thailand). Water was purified using a Milli-Q system (Millipore, Bedford, MA, USA).

\section{Microorganisms}

Streptococcus mutans (DMST 26095), S. pyogenes (DMST 17020), S. mitis (ATCC 49456T), B. subtilis, P. acnes (DMST 14916) were obtained from the Department of Medical Sciences, Ministry of Public Health, Thailand.

\section{Preparation of $\alpha$-Mangostin Enriched Extract}

G. mangostana powders (1.5 kg) was extracted with PEG 400 (3 L) using a microwave-assisted extraction (frequency of $1,450 \mathrm{MHz}$ and electric power of $900 \mathrm{Watt}$ ) at $90^{\circ} \mathrm{C}$, for $24 \mathrm{~min}$. The extract was then filtered through a filter paper and subjected to fractionation using a Diaion HP-20 column ( $8 \mathrm{~cm}$ in diameter and $100 \mathrm{~cm}$ in height). The column was eluted with 60 and $70 \%(\mathrm{v} / \mathrm{v})$ ethanol to obtain AME from the $70 \%(\mathrm{v} / \mathrm{v})$ ethanol elution after evaporated by a rotary evaporator at $45^{\circ} \mathrm{C}$.

\section{Quantitative HPLC Analysis of $\alpha$-Mangostin}

The content of $\alpha$-mangostin in MAE was analyzed using a HPLC method previously described by Bundeesomchok, et al. [16], with some modification. Briefly, the quantitative analysis was performed on a binary HPLC pump (Shimadzu 33236, Tokyo, Japan) equipped with a photodiode array detector (Shimadzu 12623, Tokyo, Japan), an autosampler (Shimadzu 03224, Tokyo, Japan) and a $150 \times 4.6 \mathrm{~mm}$ ACE 5 C18-PFP column (Advanced Chromatography Technologies, Aberdeen, Scotland). The sample injection volume was 20 $\mu \mathrm{L}$, and the column was eluted with a solution of acetonitrile and $0.2 \%$ formic acid $(70: 30, \mathrm{v} / \mathrm{v})$, at a flow rate of $1 \mathrm{~mL} /$ min. The concentration of $\alpha$-mangostin was quantified at a wavelength of $240 \mathrm{~nm}$ using a calibration curve of the authentic $\alpha$-mangostin. The calibration curve was established at five concentrations of $\alpha$-mangostin $(12.5-200 \mu \mathrm{g} / \mathrm{mL})$ by plotting peak areas against concentrations to obtain the linear equation of $\mathrm{Y}=95349 \mathrm{X}-98846\left(R^{2}=0.9995\right)$. All experiments were performed in triplicate.

\section{Determination of Antibacterial Activity}

A broth microdilution assay was used to determine the minimum inhibitory concentrations (MICs) and minimum bactericidal concentrations (MBCs) against the tested bacteria [17]. Briefly, the samples were dissolved in 


\section{International Journal of Pharmacognosy \& Chinese Medicine}

dimethyl sulfoxide and diluted with BHI broth to reach the concentration of $1,000 \mu \mathrm{g} / \mathrm{mL}$. Two-fold dilutions were then prepared in a 96-well plate. The bacterial suspension was prepared in $0.85 \%$ normal saline and the turbidity of the suspension was adjusted to the 0.5 McFarland standards (equivalent to $1 \times 10^{8} \mathrm{CFU} / \mathrm{mL}$ ). The suspension was diluted with normal saline solution to contain $1 \times 10^{6} \mathrm{CFU} / \mathrm{mL}$ and then added into each well. The final cell concentration was $5 \times 10^{5} \mathrm{CFU} / \mathrm{mL}$ and the plates were incubated at $37^{\circ} \mathrm{C}$, for $24 \mathrm{~h}$. The MICs were defined as the lowest concentration of compound that produced suppression of visible growth and the MBCs were defined as the lowest concentration of the compound to kill the microorganisms.

\section{Stability Evaluation of AME}

Stability of $\alpha$-mangostin in AME was determined using the method previously described by Puttarak, et al. [18].

\section{Effect of Light}

Two samples of AME were kept in a well-closed container and stored separately, one under protection from light and the other under exposure to fluorescent light, at room temperature $\left(30 \pm 2^{\circ} \mathrm{C}\right)$, for 16 weeks. An aliquot of the sample was taken at $0,1,2,3,4,6,8,12$ and 16 weeks and subjected to the quantitative HPLC analysis of $\alpha$-mangostin. The experiments were performed in triplicate.

\section{Effect of Temperature}

AME was kept in a well-closed container, protected from light, and stored separately at $4 \pm 2^{\circ} \mathrm{C}$ and room temperature $\left(30 \pm 2^{\circ} \mathrm{C}\right)$ for 16 weeks. An aliquot of the sample was taken at $0,1,2,3,4,6,8,12$ and 16 weeks and subjected to the quantitative HPLC analysis of $\alpha$-mangostin. The experiments were performed in triplicate.

\section{Effect of Accelerated Conditions}

AME was kept in a well-closed container, protected from light, and stored in a stability chamber at $45^{\circ} \mathrm{C}$, with $75 \%$ relative humidity for 16 weeks. An aliquot of sample was taken at $0,1,2,3,4,6,8,12$ and 16 weeks and subjected to the quantitative HPLC analysis of $\alpha$-mangostin. The experiments were performed in triplicate.

\section{Statistical Analysis}

The results are expressed as mean \pm S.D. Significant differences were analyzed using an ANOVA followed by Tukey's test. Values of $p<0.05$ were considered statistically significant.

\section{Results and Discussion}

\section{Development of a Green Method for AME}

A green method for preparation of AME was achieved by a microwave-assisted extraction using PEG 400, an alternative green solvent, for extraction of $\alpha$-mangostin. Although some alternative solvents, i.e. ethyl lactate, dimethyl carbonate, and 2-methyltetrahydrofuran, have been reported for extraction of $\alpha$-mangostin [16], they are too expensive for commercialization of $\alpha$-mangostin extract.
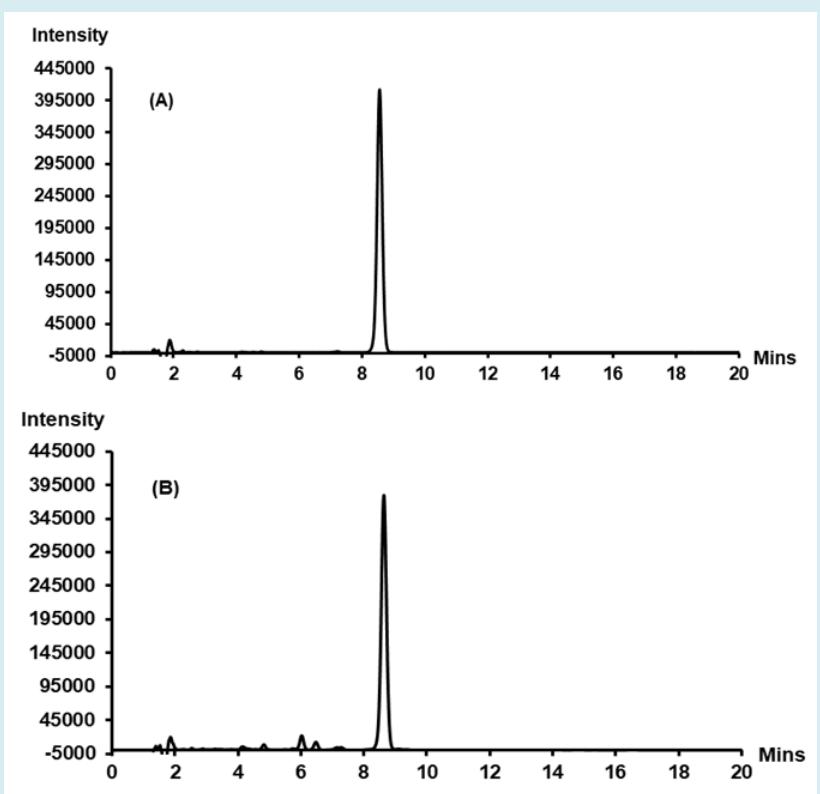

Figure 2: HPLC chromatograms of $50 \mu \mathrm{g} / \mathrm{mL}$ standard $\alpha$-mangostin (A) and AME (B). 


\section{International Journal of Pharmacognosy \& Chinese Medicine}

The present study indicated that PEG 400, usually used as a co-solvent in pharmaceutical products and cosmetics, exhibited selectivity for extraction of $\alpha$-mangostin. Although PEG 400 is miscible with water, $\alpha$-mangostin can be dissolved freely in PEG 400. This is an advantage of PEG 400 for extraction of $\alpha$-mangostin. Therefore, the obtained extract was further purified without the step of solvent evaporation. According to a non-polar molecule of $\alpha$-mangostin, the extract was subjected to a reusable hydrophobic copolymer styrene-divinylbenzene (Diaion HP-20) column, which is an adsorbent used in reverse phase chromatography. By this column, other polar compounds were excluded by $60 \%(\mathrm{v} / \mathrm{v})$ ethanol elution, while $\alpha$-mangostin was eluted and highly accumulated in the $70 \%(\mathrm{v} / \mathrm{v})$ ethanol fractions. The pooled $70 \%(\mathrm{v} / \mathrm{v})$ ethanol fractions were evaporated to obtain a yellow powder of AME ( $4.6 \mathrm{~g}$ per $1 \mathrm{~kg}$ plant powders). Based on HPLC analysis (Figure 2), AME contained a very high content of $\alpha$-mangostin $(95.6 \pm 0.59 \% \mathrm{w} / \mathrm{w})$. No toxic organic solvents were used in the process. The established method is very simple, cost effective, and environmentally friendly, which is practically used for development of commercialized products from $\alpha$-mangostin extract.

\section{Antibacterial Activity of AME}

The ethanol extract of mangosteen pericarp has been reported to possess anticariogenic activity against $S$. mutans and was suggested as a good candidate for further development of an anti-plaque agent for prevention of dental caries [13]. In addition, the active constituent enriched extracts usually produce biological effects equivalent to their pure marker compounds [8]. Therefore, the present study determined antibacterial activity of AME against the oral pathogen, including $S$. mitis, S. mutans, $S$. pyogenes, and B. subtilis compared with its pure marker compound, $\alpha$-mangostin. It was found that both of them revealed potent antibacterial activity against all tested bacteria with MICs and MBCs of $0.5-2 \mu \mathrm{g} / \mathrm{mL}$ and $4-16 \mu \mathrm{g} / \mathrm{mL}$, respectively (Table 1). The results indicated that AME may be used for the development of oral care products, such as mouthwash and toothpaste. It has been reported that $\alpha$-mangostin at a concentration of $4 \mathrm{mg} / \mathrm{mL}$ does not show any toxicity on human gingival fibroblast over a period of $8 \mathrm{~h}$ [19].

Moreover, $\alpha$-mangostin has exhibited strong anti-P. acnes activity [15]. The present study therefore determined anti- $P$. acnes activity of AME compared with $\alpha$-mangostin and found that AME and $\alpha$-mangostin exhibited equivalent anti-P. acnes activity with MIC and MBC of 2 and $8 \mu \mathrm{g} / \mathrm{mL}$, respectively (Table 1). A chromone (1,4-benzopyrone) skeletal as well as isoprenyl groups and their substituted positions may play a significant role on antibacterial activity of $\alpha$-mangostin [20].

\begin{tabular}{|c|c|c|c|c|c|c|}
\hline \multirow{2}{*}{ Microorganisms } & \multicolumn{2}{|c|}{$\alpha$-Mangostin } & \multicolumn{2}{|c|}{ AME } & \multicolumn{2}{|c|}{ Ampicillin } \\
\hline & MIC $(\mu \mathrm{g} / \mathrm{mL})$ & $\mathrm{MBC}(\mu \mathrm{g} / \mathrm{mL})$ & $\operatorname{MIC}(\mu \mathrm{g} / \mathrm{mL})$ & $\mathrm{MBC}(\mu \mathrm{g} / \mathrm{mL})$ & $\operatorname{MIC}(\mu \mathrm{g} / \mathrm{mL})$ & $\mathrm{MBC}(\mu \mathrm{g} / \mathrm{mL})$ \\
\hline S. mitis (ATCC 49456T) & 0.5 & 4 & 0.5 & 4 & 0.12 & 0.12 \\
\hline S. mutans (DMST 26095) & 1 & 8 & 1 & 16 & 0.5 & 1 \\
\hline S. pyogenes (DMST 17020) & 1 & 8 & 2 & 8 & 0.06 & 0.12 \\
\hline B. subtilis & 1 & 4 & 2 & 4 & 0.5 & 0.5 \\
\hline P. acnes (DMST 14916) & 2 & 8 & 2 & 8 & 0.12 & 0.12 \\
\hline
\end{tabular}

Table 1: Antibacterial activity of $\alpha$-mangostin, AME and ampicillin against bacterial pathogens.

\section{Stability of MAE}

The stability of MAE was evaluated by the content of $\alpha$-mangostin after storing for 16 weeks in different conditions, including light, temperature, and accelerated conditions. The results revealed that the physical appearances of AME kept in both protected and unprotected from light at $30 \pm 2^{\circ} \mathrm{C}$ were not changed throughout the period of 16 weeks. In contrast, the $\alpha$-mangostin content of AME which was exposed to light markedly decreased from 95.6 to $83.6 \% \mathrm{w} / \mathrm{w}$, while the extract kept in a light protected container was not changed throughout the storage period (Table 2). This indicated that $\alpha$-mangostin is unstable by light accelerated oxidation, common for most phenolic compounds [21].
The effect of temperature on the stability of AME was investigated under protected from light conditions at $4 \pm 2$ and $30 \pm 2^{\circ} \mathrm{C}$. Both physical appearance and $\alpha$-mangostin content of AME stored at both temperatures remained unchanged throughout the period (Table 2). The result confirmed the previous report on the stability of $\alpha$-mangostin in crude ethanolic extracts of mangosteen kept at $4^{\circ} \mathrm{C}$ and $25^{\circ} \mathrm{C}$ and protected from light for 120 days [22]. The results indicated that AME is stable under protected from light conditions even at room temperature $\left(30 \pm 2{ }^{\circ} \mathrm{C}\right)$. These findings suggested that AME should be kept in a well-closed container, protected from light, and can be stored at room temperature $\left(30 \pm 2^{\circ} \mathrm{C}\right)$. 


\section{International Journal of Pharmacognosy \& Chinese Medicine}

\begin{tabular}{|c|c|c|c|c|}
\hline \multirow{3}{*}{ Weeks } & \multicolumn{4}{|c|}{$\alpha$-Mangostin content $(\% \mathrm{w} / \mathrm{w} \pm \mathrm{SD})$} \\
\hline & \multirow{2}{*}{$\begin{array}{c}\text { Light } \\
30 \pm 2^{\circ} \mathrm{C}\end{array}$} & \multicolumn{2}{|c|}{ Protected from light } & \multirow{2}{*}{ Accelerated conditions } \\
\hline & & $30 \pm 2^{\circ} \mathrm{C}$ & $4 \pm 2^{\circ} \mathrm{C}$ & \\
\hline 0 & $95.6 \pm 0.59$ & $95.6 \pm 0.59$ & $95.6 \pm 0.59$ & $95.6 \pm 0.59$ \\
\hline 1 & $95.6 \pm 0.62$ & $95.6 \pm 0.61$ & $95.6 \pm 0.61$ & $95.6 \pm 0.58$ \\
\hline 2 & $95.5 \pm 0.60$ & $95.6 \pm 0.63$ & $95.5 \pm 0.62$ & $95.5 \pm 0.61$ \\
\hline 3 & $94.1 \pm 0.69^{*}$ & $95.5 \pm 0.67$ & $95.5 \pm 0.58$ & $95.5 \pm 0.65$ \\
\hline 4 & $91.3 \pm 0.72^{*}$ & $95.5 \pm 0.75$ & $95.5 \pm 0.57$ & $95.5 \pm 0.74^{*}$ \\
\hline 8 & $89.1 \pm 0.75^{*}$ & $95.5 \pm 0.64$ & $95.5 \pm 0.49$ & $94.2 \pm 0.66^{*}$ \\
\hline 12 & $87.4 \pm 0.61^{*}$ & $95.5 \pm 0.58$ & $95.5 \pm 0.53$ & $93.9 \pm 0.53^{*}$ \\
\hline 16 & $83.6 \pm 0.53^{*}$ & $95.4 \pm 0.57^{*}$ & $95.4 \pm 0.51^{*}$ & $92.6 \pm 0.56^{*}$ \\
\hline
\end{tabular}

* Significant difference $(p<0.05)$ when compared with the content of $\alpha$-mangostin at initial time.

Table 2: Stability evaluation of AME stored in different conditions.

Testing the stability of AME under the accelerated conditions was conducted to estimate the shelf-life of AME. If an extract is stable under the accelerated conditions or the remained content is higher than $90 \%$, it is estimated to have a 2 year-shelf-life. It was found that the physical appearances of AME were not changed throughout the period, while the content of $\alpha$-mangostin was a bit reduced from 95.6 to $92.6 \% \mathrm{w} / \mathrm{w}$ (Table 2). However, the remaining content of $\alpha$-mangostin was $96.9 \%$. Therefore, it can be implied that when kept in a well-closed container, protected from light and stored at room temperature, AME has a shelf-life of at least two years.

\section{Conflict of Interest}

The authors have declared that there is no conflict of interest.

\section{Acknowledgement}

The authors wish to thank the Thailand Research Fund (Grant No. DBG6180031) for providing a research grant, the Phytomedicine and Pharmaceutical Biotechnology Excellence Center for all laboratory facilities, and Ms. Maria Mullet for assistance with English language editing.

\section{References}

1. Zhou T, Xiao X, Li G, Cai ZW (2011) Study of polyethylene glycol as a green solvent in the microwave-assisted extraction of flavone and coumarin compounds from medicinal plants. J Chromatogr A 1218(23): 3608-3615.

2. Azwanida NN (2015) A review on the extraction methods use in medicinal plants, principle, strength and limitation. Med Aromat Plants 4(3): 2167-0412.
3. Michel T, Destandau E, Elfakir C (2011) Evaluation of a simple and promising method for extraction of antioxidants from sea buckthorn (Hippophaë rhamnoides L.) berries: Pressurised solvent-free microwave assisted extraction. Food Chem 126(3): 1380-1386.

4. Chemat F, Vian MA, Cravotto G (2012) Green extraction of natural products: concept and principles. Int J Mol Sci 13(7): 8615-8627.

5. Puttarak P, Panichayupakaranant P (2013) A new method for preparing pentacyclic triterpene rich Centella asiatica extracts. Nat Prod Res 27(7): 684-686.

6. Lateh L, Yuenyongsawad S, Chen H, Panichayupakaranant $P$ (2019) A green method for preparation of curcuminoid-rich Curcuma longa extract and evaluation of its anticancer activity. Pharmacogn Mag 15(65): 730735.

7. Sae Lim P, Yuenyongsawad S, Panichayupakaranant P (2019) Chamuangone-enriched Garcinia cowa leaf extract with rice bran oil: Extraction and cytotoxic activity against cancer cells. Pharmacogn Mag 15(61): 183-188.

8. Panichayupakaranant P (2017) Active constituent-rich herbal extracts for development of phytomedicine. Songklanagarind Med J 35(3): 187-193.

9. Zarena AS, Sankar KU (2011) Xanthones enriched extracts from mangosteen pericarp obtained by supercritical carbon dioxide process. Sep Purif Technol 80(1): 172-178.

10. Nualkaew N, Morita H, Shimokawa Y, Kinjo K, Kushiro T, et al. (2012) Benzophenone synthase from Garcinia mangostana L. pericarps. Phytochemistry 77: 60-69. 


\section{International Journal of Pharmacognosy \& Chinese Medicine}

11. Ibrahim MY, Hashim NM, Mariod AA, Mohan S, Abdulla MA, et al. (2016) $\alpha$-Mangostin from Garcinia mangostana Linn: an updated review of its pharmacological properties. Arab J Chem 9(3): 317-329.

12. Rassameemasmaung S, Sirikulsathean A, Amornchat C, Hirunrat K, Rojanapanthu P, et al. (2007) Effects of herbal mouthwash containing the pericarp extract of Garcinia mangostana L on halitosis, plaque and papillary bleeding index. J Int Acad Periodontol 9(1): 19-25.

13. Torrungruang KDDS, Vichienroj P, Chutimaworapan S (2007) Antibacterial activity of mangosteen pericarp extract against cariogenic Streptococcus mutans. CU Dent J 30: 1-10.

14. Djamaan A, Putri SD, Agustin R (2016) Formulation of toothgel from mangosteen (Garcinia mangostana L.) pericarp extract purified and its antibacterial activity against bacteria of plaque formation. Pharm Lett 8: 334339.

15. Ahmad MI, Keach JE, Behl T, Panichayupakaranant P (2019) Synergistic effect of $\alpha$-mangostin on antibacterial activity of tetracycline, erythromycin, and clindamycin against acne involved bacteria. Chin Herb Med 11(4): 412-416.

16. Bundeesomchok K, Filly A, Rakotomanomana N, Panichayupakaranant P, Chemat F (2016) Extraction of $\alpha$-mangostin from Garcinia mangostana L. using alternative solvents: Computational predictive and experimental studies. LWT-Food Sci Technol 65: 297-303.

17. Wayne PA (2008) Performance standards for antimicrobial susceptibility testing. Ninth informational supplement NCCLS document M100-S9. National committee for clinical laboratory standards, pp: 120126.

18. Puttarak P, Charoonratana T, Panichayupakaranant P (2010) Antimicrobial activity and stability of rhinacanthins-rich Rhinacanthus nasutus extract. Phytomedicine 17(5): 323-327.

19. Kaomongkolgit R, Jamdee K, Chaisomboon N (2009) Antifungal activity of alpha-mangostin against Candida albicans. J Oral Sci 51(3): 401-406.

20. Phitaktim S, Chomnawang $M$, Sirichaiwetchakoon $K$, Dunkhunthod B, Hobbs G, et al. (2016) Synergism and the mechanism of action of the combination of $\alpha$-mangostin isolated from Garcinia mangostana L. and oxacillin against an oxacillin-resistant Staphylococcus saprophyticus. BMC Microbiol 16: 195.

21. Shukla PR, Wang S, Ang HM, Tadé MO (2010) Photocatalytic oxidation of phenolic compounds using zinc oxide and sulphate radicals under artificial solar light. Sep Purif Technol 70(3): 338-344.

22. Pothitirat W, Pithayanukul P, Chomnawang MT, Supabphol R, Gritsanapan W (2009) Biological and chemical stability of mangosteen fruit rind extract. Funct Plant Sci Biotechnol 3(1): 16-18. 